\title{
Phytogenic Growth Promoter as Replacers for Antibiotic Growth Promoter in Poultry Birds
}

\section{Subha Ganguly*}

Department of Fish Processing Technology, Faculty of Fishery Sciences, West Bengal University of Animal and Fishery Sciences, Kolkata-700 094, WB, India

\begin{abstract}
The phytogenic growth promoters supplemented in the diet or added in the drinking water in the broiler birds have a promising biological effect on their growth performance, to reduce the pathogenic bacteriological load in different parts of digestive tract and to increase villus height in different segments of small intestine mainly in duodenum.
\end{abstract}

Keywords: Growth promoter; Phytogenic

\section{Introduction}

Phytogenic feed additives (often also called phytobiotics or botanicals) are commonly defined as plant-derived compounds incorporated into diets to improve the productivity of livestock through amelioration of feed properties, promotion of the individual production performance, and improving the quality of food derived from those animals, such as herbs (flowering, non woody, and non persistent plants), spices (herbs with an intensive smell or taste commonly added to human food), essential oils (volatile lipophilic compounds derived by cold expression or by steam or alcohol distillation), or oleoresins (extracts derived by non aqueous solvents). Within phytogenic feed additives, the content of active substances in products may vary widely, depending on the plant part used (e.g. seeds, leaf, root or bark), harvesting season, and geographical origin. The technique for processing (e.g. cold expression, steam distillation, extraction with non aqueous solvents etc.) modifies the active substances and associated compounds within the final product.

\section{Effect on Physiological Parameters}

The phytogenic growth promoter remains active throughout the gastrointestinal tract and as a consequence, it will exert broad spectrum antimicrobial action, will enhance nutrient utilization by exhibiting improvement in overall growth performance of broilers and by augmenting the gastrointestinal histomorphology thereby enhancing the host immunity [1].

\section{Research on Related Aspects}

Jamroz and Kamel [2] who observed improvements in daily weight gain $(8.1 \%)$ and in feed conversion ratio $(7.7 \%)$ of chickens when feed with diets supplemented $(300 \mathrm{mg} / \mathrm{kg})$ with a plant extract containing capsaicin, cinnamaldehyde and carvacrol. Biavatti et al. [3] reported Alternanthera brasiliana extracts $(180 \mathrm{ml} / 200 \mathrm{~kg}$ feed $)$ improved broiler performance from 14 to 21 days. Hernandez et al. [4] studied that blend of essential oils of cinnamon, pepper and oregano compounds improved digestibility of nutrients in chicken. Jang et al. [5] in chicken is the benefit of some natural substances on gastro intestinal enzymatic activity, most likely improving nutrient digestibility.

Burt [6] stated microbial analysis of minimum inhibitory concentration (MIC) of plant extracts from spices and herbs, as well as of pure active substances revealed levels that considerably exceeded the dietary doses when used as phytogenic feed additive. Aksit et al. [7] reported antimicrobial action of phytogenic feed additive may be in improving the microbial hygiene of carcass.
Batal and Parsons [8] indicated that micronutrients also influenced the morphology of intestines. They observed an increased height of villi of jejunum in broilers at $28^{\text {th }}$ day of age when fed with $5 \mathrm{~g}$ BioMos/ $\mathrm{kg}$ from 7 to 28 day. Jamroz et al. [9] have conducted a study that phytogenic formulations contained pungent principles (e.g. capsaicin) significantly increased intestinal mucus production.

An experiment was conducted for evaluating the efficiency or effect of the phytogenic growth promoter. The phytogenic growth promoter was active throughout the gastrointestinal tract and as a consequence, it will exert broad spectrum antimicrobial action, will enhance nutrient utilization by improving gastrointestinal histo-morphology and will augment the host immunity. In the experiment, two proven and approved phytogenic growth promoters, Digestarom 1317 (dosage $150 \mathrm{ppm}$ ) and Digestarom 1440 (dosage $800 \mathrm{ppm}$ ) AC were fed to the broiler chickens against an antibiotic growth promoter, Bacitracin Methylene Disalicylate (BMD) [10].

Digestarom AC is a combination of phytogenic components with glycerides of short chain fatty acids. Basically, Digestarom $\mathrm{AC}$ is a complex of plant extracts and plant essential oils along with monoglycerides, lactic acids and multiglyceride complexes. Being a complex of plant extracts and essential oils, Digestarom AC is hypothesized to stimulate feed intake, intestinal secretion of enzymes and enhance digestibility of nutrients. Additionally, Digestarom AC is anticipated to act as a broad spectrum antimicrobial substances throughout the gastrointestinal tract and promote development of the villus structure of the gut [10].

\section{Summary}

The phytogenic growth promoter enhance productive performance of the broiler in terms of body weight gain with minimum alteration of gut morphology and the possibility of bacterial invasion is much

*Corresponding author: Subha Ganguly, AICRP-PHT (ICAR), Department of Fish Processing Technology, Faculty of Fishery Sciences, West Bengal University of Animal and Fishery Sciences, Kolkata-700 094, WB, India; E-mail: ganguly38@gmail.com

Received May 15, 2013; Accepted May 20, 2013; Published May 22, 2013

Citation: Ganguly S (2013) Phytogenic Growth Promoter as Replacers for Antibiotic Growth Promoter in Poultry Birds. Adv Pharmacoepidem Drug Safety 2: e119. doi:10.4172/2167-1052.1000e119

Copyright: (c) 2013 Ganguly S. This is an open-access article distributed unde the terms of the Creative Commons Attribution License, which permits unrestricted use, distribution, and reproduction in any medium, provided the original author and source are credited. 
Citation: Ganguly S (2013) Phytogenic Growth Promoter as Replacers for Antibiotic Growth Promoter in Poultry Birds. Adv Pharmacoepidem Drug Safety 2: e119. doi:10.4172/2167-1052.1000e119

Page 2 of 2

less. Phytogenic growth promoter can be used as a potent replacer of antibiotic growth promoter if used at optimum level.

\section{References}

1. Ganguly S, Prasad A (2010) Role of plant extracts and cow urine distillate as immunomodulator in comparison to levamisole-a Review. J Immunol Immunopathol 12: 91-94.

2. Jamroz D, Kamel C (2002) Plant extracts enhance broiler performance. J Anim Sci 80: 41

3. Biavatti MW, Bellaver MH, Volpato L, Costa C, Bellaver C (2003) Preliminary studies of alternative feed additive for broilers: Alternanthera brasiliana extract, propolis extract and linseed oil. Rev Brasscienc Avic 5: 147-151.

4. HernÃ $n$ ndez F, Madrid J, GarcÃ $\neg a$ V, Orengo J, MegÃas MD (2004) Influence of two plant extracts on broilers performance, digestibility, and digestive organ size. Poult Sci 83: 169-174.

5. Jang IS (2006) Effect of a commercial essential oil on growth performance, digestive enzyme activity and intestinal microflora population in broiler chicks. Animal Feed Sci Tech 134: 305-315.

6. Burt S (2004) Essential oils: their antibacterial properties and potential applications in foods--a review. Int J Food Microbiol 94: 223-253.

7. Aksit M, Goksoy E, Kok F, Ozdemir D, Ozdogan M (2006) The impacts of organic acid and essential oil supplementations to diets on the microbiological quality of chicken carcasses. Arch Geflugelkd 70: 168-173.

8. Batal AB, Parsons CM (2002) Effects of age on nutrient digestibility in chicks fed different diets. Poult Sci 81: 400-407.

9. Jamroz D, Wertelecki T, Houszka M, Kamel C (2006) Influence of diet type on the inclusion of plant origin active substances on morphological and histochemical characteristics of the stomach and jejunum walls in chicken. $J$ Anim Physiol Anim Nutr (Berl) 90: 255-268.

10. Banerjee S (2011) Studies on pathobiological and bacteriological effects of phytogenic growth promoter (Digestarom AC) on broiler birds. M.V.Sc Thesis submitted to West Bengal University of Animal and Fishery Sciences, Kolkata India. 